\section{Unusual presentation of angiolymphoid hyperplasia with eosinophilia treated with intralesional and topic corticosteroid combination therapy}

Giammarco Granieri, Teresa Oranges, Salvatore Panduri, Barbara Loggini, Agata Janowska, Valentina Dini, Marco Romanelli

Department of Dermatology, University of Pisa, Italy

\begin{abstract}
Angiolymphoid hyperplasia with eosinophilia (ALHE) is an uncommon angioproliferative benign disorder. A 24year-old Caucasian female patient presented with multiple itchy reddish pearly nodule.
\end{abstract}

\section{Introduction}

Angiolymphoid hyperplasia with eosinophilia (ALHE) is an uncommon angioproliferative benign disorder first described in 1969 by Wells and Whimsterin. ${ }^{1}$ The etiology of ALHE is not clearly understood. AHLE is a locally proliferating disease which tends to involve the skin of the head and neck with single or multiple, pink to red-brown papules and/or nodules. In addition, the lesions can arise in other site of the body. ${ }^{2}$ We report an unusual case of ALHE in the skin of the left axilla which was succesfully treated using intralesional injections with triamcinolone and topical corticosteroids.

\section{Case Report}

A 24-year-old Caucasian female patient presented with multiple itchy reddish pearly nodule (4-5 $\mathrm{mm}$ in size) with defined borders, clustered over an area of $20 \times 5 \mathrm{~cm}$ in the left infra-axillary region (Figure 1). On palpation, the lesions were of smooth surface and there was no sign of lymphadenopathy. She reported that a little reddish nodule (4-5 $\mathrm{mm}$ in size) arises on the left axilla and after 3 months, multiple similar lesions near the primary lesion developed with local pruritus.

Blood investigations revealed that her absolute eosinophil count and serum immunoglobulin-E levels were within the normal limit. A skin biopsy of the most recent nodule was performed.

\section{Microscopic findings and treatment}

In the biopsied lesion, we observed lobular proliferation of vessels accompanied by a dense cellular perivascular infiltrate of lymphocytes and eosinophils which were lined by plump endothelial cells. The lymphocytic infiltrate was mainly composed of B lymphocytes and sparse lymphoid follicles (Figure 2). The histologic findings were diagnostic for ALHE.

The patient was treated with injections of triamcinolone acetonide $(40 \mathrm{mg} / \mathrm{ml})$ diluted with sterile physiological solution 1 to 3 (final dosage $13.3 \mathrm{mg} / \mathrm{ml}$ ) every two weeks for 3 months and clobetasol dipropionate $0.05 \%$ cream during the last month.

Complete resolution of the lesions occurred after 3 months of therapy and also the related itchy symptoms disappeared (Figure 3). There was no relapse during the 6 months of follow-up.

\section{Results and discussion}

ALHE also called epithelioid hemangioma is a rare benign locally proliferating condition with female preponderance, no racial differences and ranging age of 35-50 years old. The most common locations of ALHE are the head and the neck region, including the periauricular areas $(36.3 \%)$. cases of unusual localization in the trunk, hands, ${ }^{3}$ penis, ${ }^{4}$ oral mucosa and colon have been reported in literature our case reports a rare localization of this rare pathology that in the literature has been reported in a few cases. ${ }^{5-8}$

Due to the possibility of systemic involvement, in these cases a multidisciplinary team of radiologists, otolaryngologists, nephrologists, gastroenterologists and surgeons may be required to establish a correct diagnosis and optimal management.

The lesions typically present as single or multiple well-defined papules or nodules which are red, brown or purple in color. The patients with ALHE may have any of the following symptoms and signs: pruritus, pain, regional lymphadenopathy and peripheral eosinophilia. ${ }^{6}$

The exact pathogenesis of ALHE remains unknown; however, it has been proposed that ALHE may represent a proliferation of endothelial cells in response to a trauma or inflammation. In addition, recent studies proposed the role of the female hormones in the pathogenesis of ALHE which is supported by the highest incidence of the lesion in the perimenopausal, postgravidic period and in
Correspondence: Giammarco Granieri, Via Roma 67, Pisa, Italia.

Tel.: +39.3476790299

E-mail: dottor.granieri@gmail.com

Key words: Angiolymphoid hyperplasia with eosinophilia, corticosteroid therapy, infraaxilla.

Contributions: The authors contributed equally.

Conflict of interest: The authors declare no potential conflict of interest.

Funding: None.

Ethics approval: Not required (clincal practice)

Consent to publication: Received.

Please cite this article as: Granieri $G$, Oranges T, Panduri S, et al. Unusual presentation of angiolymphoid hyperplasia with eosinophilia treated with intralesional and topic corticosteroid combination therapy. Dermatol Rep 2021;13:9063.

Received for publication: 30 December 2020 Revision received: 24 February 2021.

Accepted for publication: 30 March 2021.

This work is licensed under a Creative Commons Attribution-NonCommercial 4.0 International License (CC BY-NC 4.0).

C Copyright: the Author(s), 2021

Licensee PAGEPress, Italy

Dermatology Reports 2021; 13:9063

doi:10.4081/dr.2021.9063

association with the use of oral contraceptives.

The lesions display specific histologic features mainly located in dermis and less frequent in subcutaneous tissues. The histopathology reveals proliferation of the vessels with large endothelial cells which contain an abundant eosinophilic cytoplasm. The cells are mostly cuboidal with cytoplasmic vacuolation and lobulated nuclei. A dense vascular and interstitial infiltrate of eosinophiles and lymphocytes is seen. The immunohistochemical exams highlight the positivity of the endothelial cells for the Von Willebrand factor, CD31 and CD34 but the negativity for the keratin. ${ }^{9}$

The main differential diagnoses are: Kimura disease, pyogenic granuloma, epithelioid hemangioendothelioma and Kaposi sarcoma. ALHE tends to be chronic and non-remittent and its treatment is guided by the number and the size of lesions and the patient's general health.

The gold standard treatment is the radical surgical excision; but these lesions 


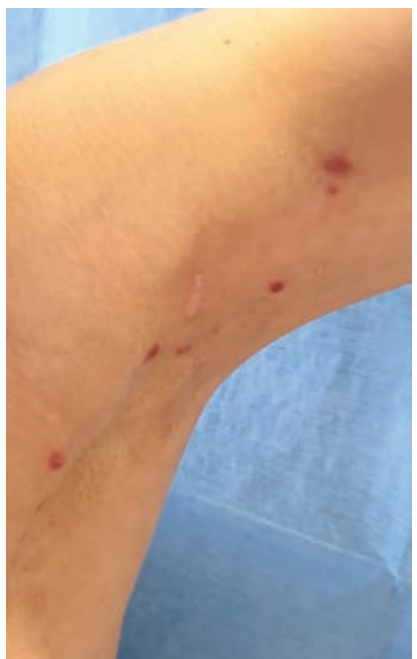

Figure 1. Infra-axillary ALHE before treatment: multiple reddish pearly nodules with defined borders $(282 \times 453 \mathrm{~mm})$.

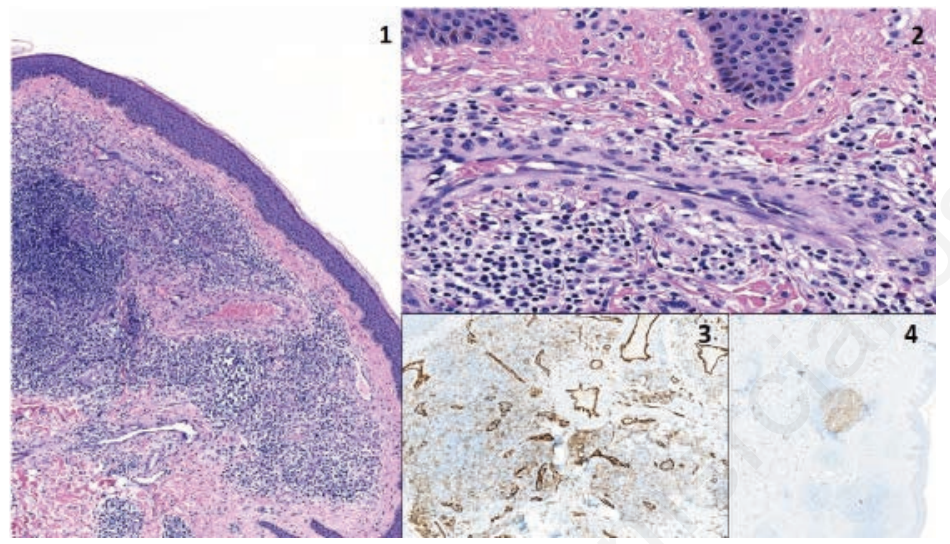

Figure 2. (Panel 1: 6x) The lesion is characterized by a nodular dermal perivascular infiltrate; vessels are ectatic; at a higher resolution (Panel 2: 14x) the lesion consisted of vessels lined by plump endothelial cells and a cellular infiltrate composed by lymphocytes and sparse eosinophils. Immunohistochemichemistry: CD34 positivity in endothelial cells (Panel 3: 5x), CD21 immunocoloration evidenced the presence of lymphoid follicles (Panel 4: x2).

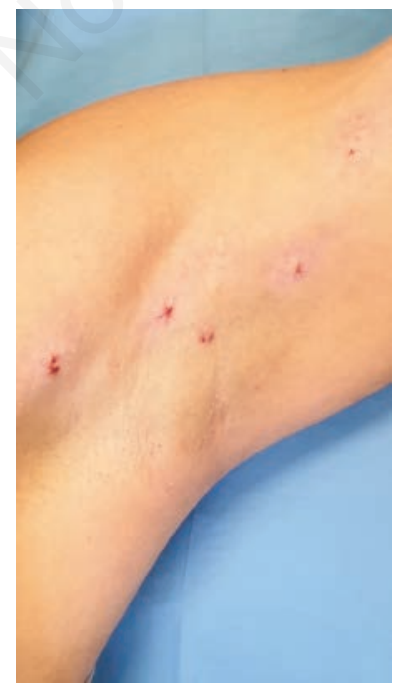

Figure 3. ALHE after 3 months of topical and injection therapy: the complete disappearance of the nodules can be noted $(283 \times 509 \mathrm{~mm})$. can also be treated by pulsed-dye la-ser, 10 carbon dioxide laser, ${ }^{11}$ electro-desiccation, cryotherapy, ${ }^{12}$ systemic corticosteroids, intra-lesional injection of corticosteroids or sclerosing agents, intra-muscular injection of corticosteroids, 13 photodynamic therapy, 7 interfer-on alpha- $2,{ }^{13}$ isotretinoin and tacrolimus. ${ }^{14-16}$

\section{Conclusions}

We reported this case for the rarity of the disease and for its unusual localization so we demonstrated the good aes-thetic result of the therapeutic combination of topical clobetasol and intralesional triamcinolone acetonide.

\section{References}

1. Wells GC, Whimster IW. Subcutaneous angiolymphoid hyperplasia with eosinophilia. Br J Dermatol 1969;81:114.

2. Fontana SC, Borgstadt A, Fraga GR et al. Angiolymphoid Hyperplasia With Eosinophilia Within a Vascular Malformation: Case Report and Review of the Literature. Ann Otol Rhinol Laryngol 2016;125:775-8.

3. Arnold M, Geilen CC, Coupland SE et al. Unilateral angiolymphoid hyperplasia with eosinophilia involving the left arm and hand. J Cutan Pathol 1999;26:43640.

4. Dewan P, Francis ND, Lear JT, Bunker CB. Angiolymphoid hyperplasia with eosinophilia affecting the penis. $\mathrm{Br} \mathrm{J}$ Dermatol 2008;159:755-7.

5. Nonose R, Priolli DG, Cardinalli IA et al. Epithelioid hemangioma of the colon: a case report. Sao Paulo Med J 2008;126:294-6.

6. Olsen TG, Helwig EB. Angiolymphoid hyperplasia with eosinophilia. A clinicopathologic study of 116 patients. J Am Acad Dermatol 1985;12:781-96.

7. Guo R, Gavino AC. Angiolymphoid hyperplasia with eosinophilia. Arch Pathol Lab Med 2015;139:683-6.

8. Parmar NV, Sandu J, Kanwar AJ, Saikia UN. Angiolymphoid hyperplasia with eosinophilia of the infra-axillary region: report of a case. Dermatol Online J 2014;20.

9. Kempf W, Haeffner AC, Zepter K, et al. Angiolymphoid hyperplasia with eosinophilia: evidence for a T-cell lymphoproliferative origin. Hum Pathol 2002;33:1023-9.

10. Abrahamson TG, Davis DA. Angiolymphoid hyperplasia with 
eosinophilia responsive to pulsed dye laser. J Am Acad Dermatol 2003;49:S195-6.

11. Kaur T, Sandhu K, Gupta S et al. Treatment of angiolymphoid hyperplasia with eosinophilia with the carbon dioxide laser. J Dermatolog Treat 2004;15:328-30.

12. Woźniacka A, Omulecki A, Torzecka JD. Cryotherapy in the treatment of angiolymphoid hyperplasia with eo- sinophilia. Med Sci Monit 2003;9:CS14.

13. Shenefelt PD, Rinker M, Caradonna S. A case of angiolymphoid hyperplasia with eosinophilia treated with intralesional interferon alfa-2a. Arch Dermatol 2000;136:837-9.

14. Carlesimo M, Mari E, Tammaro A et al. Angiolymphoid hyperplasia with eosinophilia treated with isotretinoin. Eur J Dermatol 2007;17:554-5.
15. Mashiko M, Yokota K, Yamanaka Y, Furuya K. A case of angiolymphoid hyperplasia with eosinophilia successfully treated with tacrolimus ointment. Br J Dermatol 2006;154:8034.

16. Braun-Falco M, Fischer S, Plötz SG, Ring J. Angiolymphoid hyperplasia with eosinophilia treated with antiinterleukin-5 antibody (mepolizumab). Br J Dermatol 2004;151:1103-4. 